\title{
Acute Kidney Injury Relevant to Tubulointerstitial Nephritis with Late-Onset Uveitis Superimposed by Thrombotic Microangiopathy: A Case Report and Review of the Literature
}

\author{
Youlu Zhao ${ }^{\text {a-d }}$ Junwen Huang ${ }^{\text {a-d }}$ Tao Su ${ }^{\text {a-d }}$ Zhikai Yang ${ }^{\text {a-d }}$ Xizi Zheng ${ }^{\text {a-d }}$ \\ Liu Yang ${ }^{e}$ Xujie Zhou ${ }^{\text {a-d }}$ Xiaojuan Yu ${ }^{\text {a-d }}$ Hui Wang ${ }^{\text {a-d, } f}$ Suxia Wang ${ }^{\text {a-d, } f}$ \\ Gang Liu ${ }^{\mathrm{a}-\mathrm{d}}$ Li Yang $^{\mathrm{a}-\mathrm{d}}$

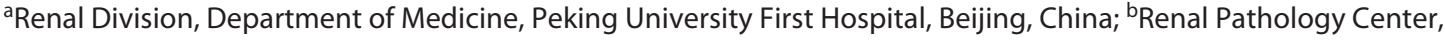 \\ Peking University Institute of Nephrology, Beijing, China; 'Key Laboratory of Renal Disease, Ministry of Health of \\ China, Beijing, China; ${ }^{d}$ Key Laboratory of Chronic Kidney Disease Prevention and Treatment (Peking University),

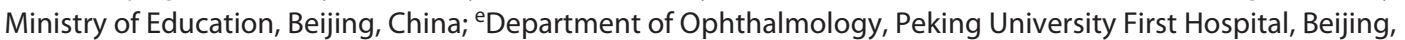 \\ China; fLaboratory of Electron Microscopy, Pathological Centre, Peking University First Hospital, Beijing, China
}

\section{Keywords}

Acute kidney disease · Acute kidney injury •

Tubulointerstitial nephritis and uveitis - Thrombotic microangiopathy · Acute tubulointerstitial nephritis

\footnotetext{
Abstract

Background: The syndrome of tubulointerstitial nephritis and uveitis (TINU) is an uncommon and multisystemic autoimmune disorder. This review reports a rare case of TINU being superimposed on thrombotic microangiopathy (TMA) and, by comparing with the available literature, also summarizes the clinical features, associated conditions, treatment, and outcome of patients with TINU. Summary: Herein, we report the case of a 37-year-old male patient with acute kidney injury (AKI) clinicopathologically identified as malignant hypertension-induced TMA superimposed by acute tubulointerstitial nephritis, which was suspected to be related to drug hypersensitivity. After treatment with oral prednisone combined with a renin-angiotensin system inhibitor, the pa-
}

tient achieved partial renal recovery and was withdrawn from hemodialysis. Recurrent AKI concomitant with new-onset asymptomatic uveitis was detected during routine clinical follow-up after cessation of prednisone. TINU was then diagnosed, and prednisone followed by cyclophosphamide was prescribed. The patient achieved better renal recovery than in the first round of treatment and maintained stable renal function afterward. By reviewing the literature, 36 cases were reported as TINU superimposed on other conditions, including thyroiditis, osteoarthropathy, and sarcoid-like noncaseating granulomas. Key messages: TINU could be complicated by many other conditions, among which TMA is very rare. When presented as AKI, kidney biopsy is important for differential diagnosis. The case also shows that recurrent AKI with concomitant uveitis after prednisone withdrawal strongly suggested the need for long-term follow-up and elongated prednisone therapy for TINU syndrome.

(C) 2020 The Author(s)

Published by S. Karger AG, Basel karger@karger.com www.karger.com/kdd

Karger $\stackrel{\text { ' }}{=}$

BOPEN ACCESS
(C) 2020 The Author(s)

Published by S. Karger AG, Basel

This article is licensed under the Creative Commons AttributionNonCommercial-NoDerivatives 4.0 International License (CC BYNC-ND) (http://www.karger.com/Services/OpenAccessLicense) Usage and distribution for commercial purposes as well as any distribution of modified material requires written permission.
Dr. Li Yang

Renal Division, Department of Medicine

Institute of Nephrology, Peking University, Peking University First Hospital

Xishiku Street No. 8, Beijing 100034 (China)

li.yang@bjmu.edu.cn 


\section{Introduction}

Acute kidney injury (AKI) is a common and multifaceted syndrome that is categorized according to the underlying pathophysiology related to different insults [1]. The etiology of AKI is complicated and includes decreased renal perfusion, urinary tract obstruction, and large-scale parenchymal diseases. Identifying the cause of AKI, especially the types of parenchymal injury, is critical, as specific therapeutic regimens are needed to reverse the pathophysiologic changes in the kidneys. However, in many cases, there are multiple injury insults, which make the diagnosis and treatment of AKI more challenging.

Acute tubulointerstitial nephritis (ATIN) is a common type of parenchymal AKI with various etiologies. Tubulointerstitial nephritis and uveitis (TINU) syndrome used to be regarded as a rare cause of ATIN, and more attention has been drawn to it due to the knowledge of its potential for missed diagnosis $[2,3]$. It has been reported that establishing a diagnosis of the TINU syndrome is sometimes difficult, as ocular manifestations could be asymptomatic or appear later than renal injury [4]. Thrombotic microangiopathy (TMA) is a life-threatening condition characterized by endothelial injury induced by various disease conditions. AKI is common in patients with TMA, which is mainly due to the ischemic injury caused by arterial intima lesions and glomerular endothelial lesions. Here, we describe a case of hemodialysis requiring AKI with late-uveitis TINU syndrome, superimposed by malignant hypertension-induced TMA. The differential diagnosis and the corresponding treatment are discussed.

\section{Case Presentation}

A 37-year-old male patient presented to our hospital with "significant hypertension and progressive renal dysfunction." Five years ago, he was diagnosed with hypertension of 130/90-160/120 $\mathrm{mm} \mathrm{Hg}$, with normal urinalysis and normal serum $\mathrm{Cr}$ (SCr) level. No further evaluation or treatment was administered. Two years ago, his blood pressure was between 150/100 and 160/110 mm Hg, which peaked at 200/120 mm Hg half a year ago, with blurred vision and fundus changes observed by fundoscopy examination. However, he had not been on any routine antihypertensive medications until 2 months ago when telmisartan, metoprolol, and 1-amlodipine were prescribed. One month before admission, he felt nausea and fatigue, with a blood pressure of $160 / 120 \mathrm{~mm} \mathrm{Hg}$, and his blood test showed an SCr level of $935.9 \mu \mathrm{mol} / \mathrm{L}$ (normal range: 44$133 \mu \mathrm{mol} / \mathrm{L}$ ). Fundoscopy examination revealed fundal hemorrhage, and malignant hypertension (MHT) was diagnosed. Echocardiography and neurological examinations were normal. Renal ultrasound showed normal kidney size with no evidence of urinary tract obstruction. His SCr rapidly increased to $2,640 \mu \mathrm{mol} / \mathrm{L}$ within
2 weeks with a urine volume of less than $300 \mathrm{~mL} /$ day. Hemodialysis was initiated, and he was referred to our hospital.

AKI was diagnosed on admission, and the causes were carefully screened. Laboratory tests showed mild proteinuria $(1.31 \mathrm{~g} / 24 \mathrm{~h})$ with clear urine sediment, which did not support proliferative glomerulonephritis. The patient had significantly decreased urine-concentrating ability, with a urine/blood osmolality of 217/307 mOsm/ $\mathrm{kg}$. An obvious proximal tubular dysfunction was defined as the patient had renal glycosuria (urine/blood glucose: $3+/ 5.32 \mathrm{mmol} / \mathrm{L}$ ), elevated urine al-microglobulin level $(214 \mathrm{mg} / \mathrm{L}$, normal range $0-12 \mathrm{mg} / \mathrm{L})$, and increased fractional excretion of sodium $(\mathrm{FeNa})$ (10\%). After careful inquiry of medication history, the patient claimed that he had been taking a locally bought herbal medicine for 2 weeks before his SCr was found to be elevated. As a result, druginduced acute tubular necrosis (ATN) or ATIN was suspected.

As MHT can lead to TMA, which further results in kidney injury, systemic screening for TMA was performed. Platelet count, reticulocyte count, lactate dehydrogenase, and total bilirubin were normal. There was no red cell fragmentation detected by peripheral blood smear examination. Essential hypertension was suspected after the exclusion of renovascular and endocrine hypertension.

Renal biopsy was performed to identify the cause of AKI. Immunofluorescence examination was negative. There was marked glomerular ischemia and shrinkage with significant arteriolar impairment, including endothelial swelling, intimal mucoid edema, and onion-skin lesion formation with narrowed arteriolar lumen. There were diffuse tubulointerstitial inflammatory infiltrates, mainly mononuclear cells with scattered neutrophils and eosinophils, suggesting acute ongoing inflammation. Focal tubular atrophy and interstitial fibrosis were also observed. Electron microscopy confirmed the final pathological diagnosis as TMA (possibly secondary to MHT) superimposed by ATIN (Fig. 1). After ruling out infectious and immunological diseases related to ATIN by serum tests and ocular examination, drug-induced ATIN (D-ATIN) was diagnosed.

With support of hemodialysis, telmisartan was prescribed for the treatment of MHT-induced TMA, and oral prednisone was administered at $30 \mathrm{mg} /$ day for 6 weeks and gradually tapered to $5 \mathrm{mg} /$ day for treating D-ATIN. The SCr level gradually decreased to $304.3 \mu \mathrm{mol} / \mathrm{L}$ with the $\mathrm{Cr}$ clearance rate improving to $24.92 \mathrm{~mL} /$ $\min / 1.73 \mathrm{~m}^{2} 4$ months after biopsy. Hemodialysis was withdrawn and prednisone treatment lasted for a total of 6 months. Four months after prednisone cessation (10 months after biopsy), the patient developed acute kidney disease with an asymptomatic and gradual increase in SCr, from 340 to $383 \mu \mathrm{mol} / \mathrm{L}$ and then to 430 $\mu \mathrm{mol} / \mathrm{L}$, within 2 months. The patient also had recurrent renal glycosuria and elevation of urine a1-microglobulin (from 142 to 227 $\mathrm{mg} / \mathrm{L}$ ). The high-sensitivity C-reactive protein increased from 1.21 to $4.95 \mathrm{mg} / \mathrm{L}$ (normal range $0-3 \mathrm{mg} / \mathrm{L}$ ). These results were highly suggestive of a relapse of ATIN, and repeated ocular examination revealed new-onset bilateral uveitis (Fig. 2), yet anti-modified Creactive protein $(\mathrm{mCRP})$ autoantibody (mCRP-Ab) was negative. After ruling out infectious and other systemic diseases related to ATIN, TINU syndrome was diagnosed. Oral prednisone at $15 \mathrm{mg} /$ day was reinitiated, and the SCr level decreased to $309 \mu \mathrm{mol} / \mathrm{L}$ with an alleviation of tubular dysfunction 6 weeks later. Prednisone was then tapered to $10 \mathrm{mg} /$ day and oral cyclophosphamide (CTX, 50 $\mathrm{mg}$ qod) was added. The accumulative dosage of CTX was $6 \mathrm{~g}$, and the second round of prednisone treatment lasted for 11 months. The patient had further renal recovery, with the SCr remaining at $280 \mu \mathrm{mol} / \mathrm{L}$ and the $\mathrm{Cr}$ clearance rate reaching $45 \mathrm{~mL} / \mathrm{min}$ (Fig. 1).
AKI due to TINU Superimposed by

Thrombotic Microangiopathy
Kidney Dis 2020;6:414-421

DOI: $10.1159 / 000507668$ 

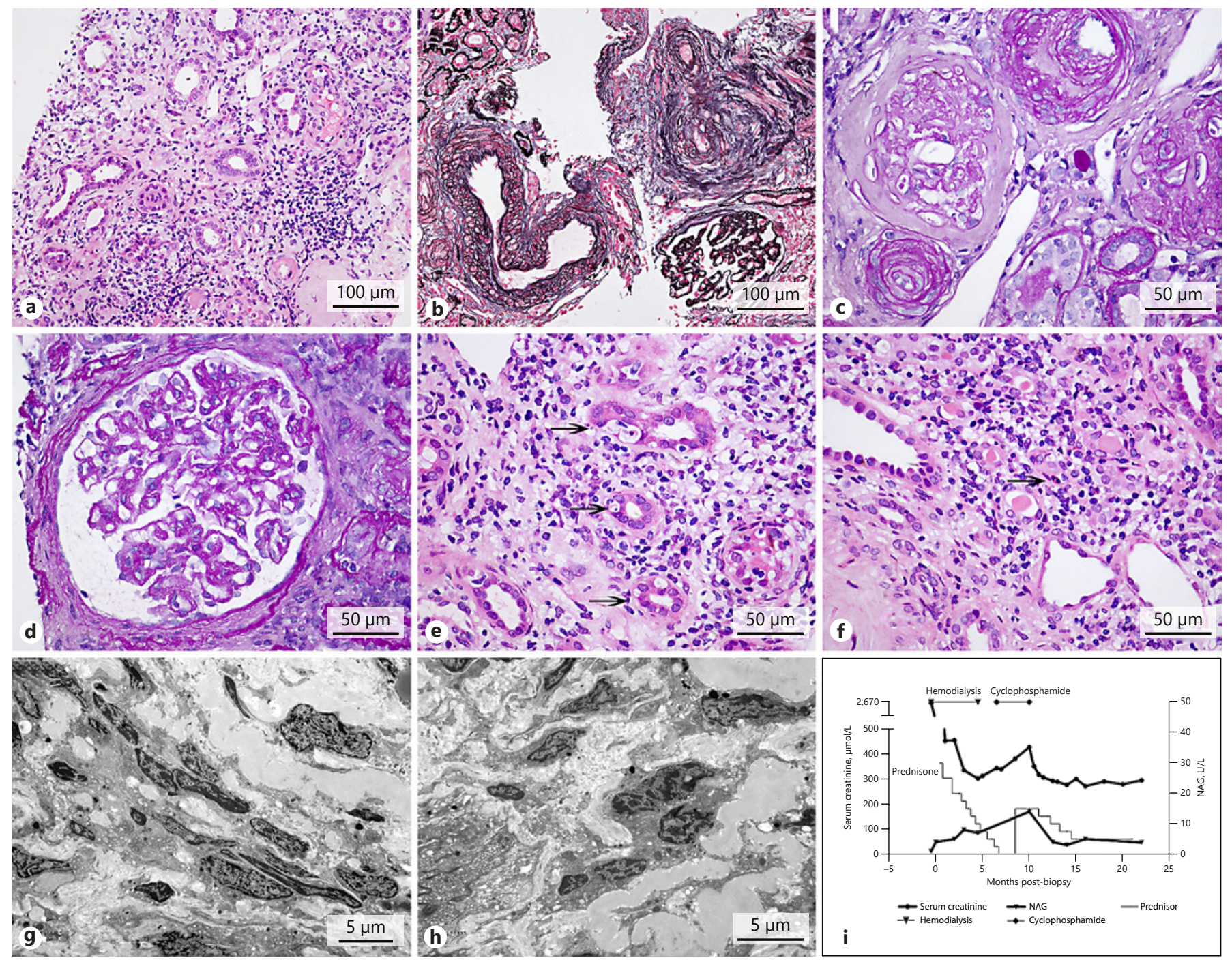

Fig. 1. Representative light microscopy and electron microscopy images of renal involvement in this patient. a, b HE staining and PASM + Masson staining, respectively, $\times 20$. Even at low magnification, acute interstitial nephritis and thrombotic angiopathy are clearly visible. $\mathbf{c}$ PAS stain, $\times 40$. Intimal proliferation and fibrosis with narrowed lumens of arterioles/interlobular arteries give rise to the so-called onion-skin lesions. d PAS, $\times 40$. Glomerular ischemia and shrinkage. e HE, $\times 40$. Tubulitis (black arrows). $\mathbf{f ~ H E , ~}$ $\times 40$. Interstitial infiltration of scattered eosinophil (black arrow). g, h Electron microscopy, $\times 5,000$. Ultrastructural analysis confirmed wrinkled glomerular basement membrane; atrophic tubules as well as interstitial infiltration of lymphocytes and monocytes with no dense deposits. i Curve of SCr and relevant immunosuppressive management. HE, hematoxylin and eosin; PASM, periodic acid-silver methenamine; PAS, periodic acid-Schiff; SCr, serum creatinine.

\section{Discussion and Conclusion}

\section{TINU Overlapping with Other Disorders}

First described by Dobrin in 1975, TINU is an uncommon disorder. We searched the MEDLINE database, using PubMed, for reports concerning "uveitis" and "interstitial nephritis" or "tubulointerstitial nephritis," with additional publications identified by screening the references, reveal- ing around 226 adult cases written in English, among which 36 cases were reported as TINU superimposed on other conditions. TINU syndrome overlaid by TMA has not been previously described. Given the potential for broad immunologic dysregulation in the current pathogenetic construct of TINU, it is not surprising that the inflammatory process may involve other organs besides the eyes and kidneys (the details are listed in Table 1). 

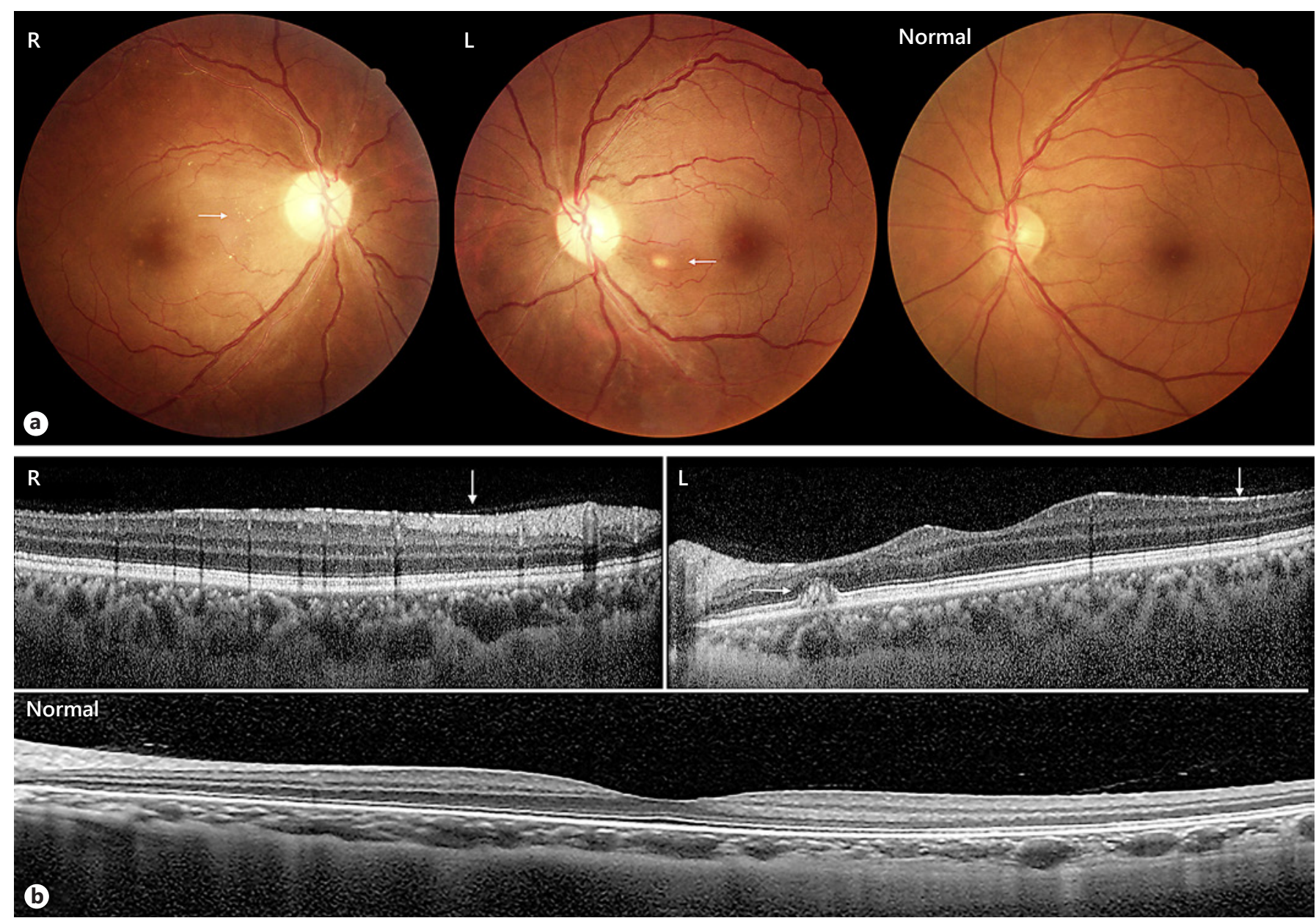

Fig. 2. a Fundus photograph of both eyes showing multifocal chorioretinal lesions (shown by white arrows, with the right side heavier). $\mathbf{b}$ Optical coherence tomography of the right eye with evidence of marked macular edema and epiretinal membrane, and the left eye with evidence of epiretinal membrane and focal lesion with high reflectivity (white arrows).

Three case reports detail the occurrence of thyroiditis in patients with TINU, with the thyroid function returning back to normal as the renal and ocular manifestations of TINU responded to corticosteroid therapy [5-7]. Two cases raise the awareness of possible osteoarthropathic involvement in TINU [8-10], possibly due to a similar pathogenetic mechanism to that of reactive arthritis. Lymphoid interstitial lung disease has been reported in association with TINU [11], where the pulmonary lesion proved steroid responsive but flared after initially remitting. Other disorders, including hypoparathyroidism [12], immunoglobulin A nephropathy [5], immunoglobulin G4-related disease [13], cytoplasmic anti-neutrophil cytoplasmic antibodies positive [14], nephrogenic fibrosing dermopathy [15], Crohn's disease [16], and neuro-

AKI due to TINU Superimposed by Thrombotic Microangiopathy
Sweet disease [17], have been reported to be associated with TINU.

TINU may be difficult to be differentiated from sarcoidosis because it is not unusual for sarcoid patients to present with uveitis and interstitial kidney diseases. Moreover, in many reported cases of TINU, the kidneys [18-20], liver [21], and bone marrow [19, 22, 23] have demonstrated sarcoid-like noncaseating granulomas. In these cases, the diagnosis of TINU was favored over that of sarcoidosis due to the absence of pulmonary involvement or increased angiotensin-converting enzyme inhibitor activity or increased urinary beta- 2 microglobulin (B2M).

Evidence of tubular dysfunction is abundant in case reports. Fanconi complex [24-30], nephrogenic diabetes 
Table 1. Literature review of TINU overlapping with other disorders

\begin{tabular}{|c|c|c|c|c|c|}
\hline Complication & $\begin{array}{l}\text { Age range, } \\
\text { years }\end{array}$ & $\begin{array}{l}\text { Case, } \\
\mathrm{n}\end{array}$ & $\begin{array}{l}\text { Gender } \\
\text { (male/female) }\end{array}$ & Treatment & Prognosis \\
\hline Thyroid involvement [5-7] & $64-69$ & 3 & $0 / 3$ & $\begin{array}{l}\text { Corticosteroids, } \\
\text { methotrexate, } \\
\text { cyclosporine A, and } \\
\text { mycophenolate mofetil }\end{array}$ & $\begin{array}{l}\text { Improvement of renal and thyroid } \\
\text { function }\end{array}$ \\
\hline Osteoarthropathy [8-10] & $19-56$ & 2 & $1 / 1$ & NA & NA \\
\hline Lymphoid interstitial lung disease [11] & 41 & 1 & $0 / 1$ & Corticosteroids & Lung disease relapsed \\
\hline Hypoparathyroidism [12] & 26 & 1 & $0 / 1$ & Corticosteroids & $\begin{array}{l}\text { Renal function improved and PTH } \\
\text { remained within the normal range }\end{array}$ \\
\hline IgA nephropathy [5] & 64 & 1 & $0 / 1$ & Corticosteroids & Improved \\
\hline IgG4-related disease [13] & 50 & 1 & $0 / 1$ & Corticosteroids & Symptoms improved \\
\hline cANCA positive [14] & 47 & 1 & $0 / 1$ & Corticosteroids & $\begin{array}{l}\text { Symptoms improved and cANCA } \\
\text { remained positive }\end{array}$ \\
\hline Nephrogenic fibrosing dermopathy [15] & 53 & 1 & $1 / 0$ & $\begin{array}{l}\text { Corticosteroids and } \\
\text { cyclosporine A }\end{array}$ & $\begin{array}{l}\text { Hemodialysis, plaques, and edema } \\
\text { reduced }\end{array}$ \\
\hline Crohn's disease [16] & 43 & 1 & $1 / 0$ & Corticosteroids & Symptoms improved \\
\hline Neuro-Sweet disease [17] & 59 & 1 & $0 / 1$ & $\begin{array}{l}\text { Corticosteroids and } \\
\text { adalimumab }\end{array}$ & $\begin{array}{l}\text { Normal neurologic examination, } \\
\text { asymptomatic }\end{array}$ \\
\hline $\begin{array}{l}\text { Sarcoid-like noncaseating granulomas in the } \\
\text { kidneys [18-20], liver [21], and bone marrow } \\
{[19,22,23]}\end{array}$ & $35-64$ & 9 & $3 / 6$ & Corticosteroids & Renal function improved, 1 relapsed \\
\hline $\begin{array}{l}\text { Renal tubular dysfunction, including Fanconi } \\
\text { syndrome [24-30], nephrogenic diabetes } \\
\text { insipidus [19], and Sjogren's syndrome [31] }\end{array}$ & $23-57$ & 9 & $1 / 8$ & $\begin{array}{l}\text { Corticosteroids and } \\
\text { colchicine }\end{array}$ & Asymptomatic, normal parameters \\
\hline $\begin{array}{l}\text { Infections associated with TINU, including EBV } \\
{[32,33] \text {, varicella zoster virus [34], HTLV-1 [35], }} \\
\text { and chlamydia [36] }\end{array}$ & $43-59$ & 4 & $1 / 3$ & $\begin{array}{l}\text { Without systemic } \\
\text { treatment in patients } \\
\text { with EBV; chemotherapy } \\
\text { and Ara-C }\end{array}$ & $\begin{array}{l}\text { Clinical status improved except } 1 \\
\text { patient with chronic active EBV } \\
\text { disease died from treatment-related } \\
\text { death at } 6 \text { years }\end{array}$ \\
\hline $\begin{array}{l}\text { Drugs such as Chinese herb (goresian) [37], } \\
\text { flurbiprofen intake [38], ibuprofen and dipyrone } \\
\text { [39], and synthetic cannabinoid [40] associated } \\
\text { with TINU }\end{array}$ & $42-58$ & 4 & $1 / 3$ & $\begin{array}{l}\text { Culprit medications } \\
\text { stopped, corticosteroids }\end{array}$ & Symptoms improved \\
\hline
\end{tabular}

PTH, parathyroid hormone; EBV, Epstein-Barr virus; HTLV-1, human T-cell leukemia virus; c-ANCA, cytoplasmic antineutrophil cytoplasmic antibodies; IgA, immunoglobulin A; IgG4, immunoglobulin G4; TINU, tubulointerstitial nephritis and uveitis; NA, not applicable.

insipidus [19], and Sjogren's syndrome [31] featuring as distal renal tubular acidosis have been present.

Environmental exposures may play a role. Infectious etiologies have been suggested to trigger TINU, including Epstein-Barr virus [32,33], varicella zoster virus [34], human T-cell leukemia virus-1 [35], and chlamydia [36]. Although efforts have been made to ascribe TINU to drugs, including Chinese herb (goresian) [37], ibuprofen and dipyrone [38], flurbiprofen intake [39], and synthetic cannabinoid [40], no definite documentation of causality has been made.

\section{Significance of Renal Biopsy in AKI}

AKI is a highly heterogeneous, common, and potentially devastating condition, which needs fast differential diagnosis and proper treatment strategy. It is acknowledged that clinical assessment and laboratory testing for the differential diagnosis of AKI could be inaccurate, especially in cases with coexisting injury insults or having AKI superimposed on preexisting CKD. Previous studies have shown that histopathologic and prebiopsy clinical diagnoses differed in 15-34\% of elderly patients with 
acute renal insufficiency, with many of them involving potentially treatable entities $[41,42]$.

The current case was clinically considered MHT-induced AKI, whereas a hint of significant acute proximal tubular dysfunction suggested a possibility of additional renal injury from ATN or ATIN where immunosuppressive therapy was in dilemma. With renal biopsy, ATIN superimposed on MHT-induced TMA was diagnosed, which directed a timely combination treatment including both renin-angiotensin system (RAS) inhibition and prednisone. The relapse of AKI due to recurrent ATIN after prednisone cessation and a better renal recovery achieved by the second round of more intensive and longer immunosuppressive treatment suggested a greater contribution of ATIN than MHT-induced TMA to the development of AKI in this patient. Our case reinforces the significance of kidney biopsies in the differential diagnosis and treatment of AKI.

\section{TMA Superimposed by ATIN}

MHT-induced TMA predominantly affects arterioles and interlobular arteries, which induces nephron ischemia and hypoxia, causing secondary tubulointerstitial impairment $[43,44]$. In the acute stage, ATN may occur, whereas in the later stage, tubular atrophy and interstitial fibrosis with mononuclear cell infiltration are common. The tubular and interstitial lesions are focal and accompanied by ischemic glomeruli, which is the feature of tubulointerstitial injury secondary to the ischemia and hypoxia resulting from vascular lesions [44].

In the current case, however, the tubulointerstitial impairment is diffusely distributed and not limited to the regions of ischemic glomeruli, with large amounts of inflammatory infiltrates comprising not only mononuclear cells but also eosinophils and neutrophils, all of which indicate an independent hit of ATIN superimposed upon the basal MHT-induced TMA-related lesions. The response to steroid therapy and the followed disease course supported this diagnosis.

\section{Missed Diagnosis of Late-Uveitis TINU Syndrome}

Accumulated evidence has shown that the incidence of TINU syndrome might be significantly underestimated [45]. In the current case, the diagnosis of TINU syndrome was rather difficult. There were neither immunologic disorders by serum examination nor uveitis through ophthalmological examination. The assay of mCRP-Ab was also negative. In addition, the patient claimed a herbal medication intake history before the detection of kidney injury. All of these misled the clinician to make the diag- nosis of D-ATIN. However, a relapse of ATIN and concurrent asymptomatic bilateral uveitis were detected after prednisone cessation during follow-up, which was 10 months after renal biopsy and led to correction of the diagnosis. A previous prospective study about pediatric TINU patients recommended that the ophthalmological follow-up of all patients with TIN is warranted for at least 12 months, starting with 3-month intervals [46].

Previous studies have shown that late-uveitis TINU syndrome is likely to be misdiagnosed as D-ATIN, since the 2 diseases are clinically and pathologically indistinguishable at the time of renal biopsy [47-49]. Although positive $\mathrm{mCRP}-\mathrm{Ab}$ is regarded as helpful in distinguishing patients with TINU syndrome from those with D-ATIN, its diagnostic value is still limited (specificity $88 \%$ and sensitivity 64\%) [48]. It is noteworthy that the relapse of ATIN and uveitis could be completely asymptomatic, and therefore, routine and long-term follow-up of patients with ATIN is essential for identifying late-uveitis TINU syndrome, which is of critical importance during the period of prednisone cessation, as the relapse of the disease most often occurs within 4-18 months after biopsy when prednisone is stopped or tapered to $2.5-10 \mathrm{mg} /$ day [50].

\section{Treatment for TINU Syndrome}

Both MHT-induced TMA and ATIN contributed to the acute decline in renal function in the current case, and partial renal recovery was achieved by comprehensive treatments, including RAS inhibition on the basis of hemodialysis and steroid medication. RAS inhibitors could suppress ischemia-induced activation of the renin-angiotensin-aldosterone system, reduce endothelial injury, help maintain dialysis independence, and improve longterm outcome [51]. However, the misdiagnosis of DATIN led the clinician to prescribe relatively short-term steroid therapy, and the patient presented with acute kidney disease relapse (late-uveitis TINU syndrome). A second round of prednisone was administered, and CTX was added during prednisone dose reduction. Immunosuppressive therapy lasted for a total of 11 months, and the patient had better renal recovery and his renal function remained stable afterward.

There have been no evidence-based protocols for treating patients with TINU syndrome [52]. Case reports have suggested alternate immunosuppressive therapies, such as CTX [53], azathioprine [54], mycophenolate mofetil [55], and cyclosporine A [56], on the basis of steroid therapy. However, how long immunosuppressive therapy should be extended (especially in patients with recurrent kidney injury), whether additional immuno- 
suppressive medications should be added, and what combination of medications is preferred need further studies to be determined.

Defining the causes of AKI is critical, and renal biopsy is essential in complicated cases. TINU syndrome can superimpose upon baseline kidney diseases and is easy to be misdiagnosed. Regular long-term follow-up of patients with ATIN is the most effective way, so far, to identify late-uveitis TINU syndrome, make proper treatment, and promise a better renal outcome.

\section{Acknowledgement} study.

The authors wish to thank the patient who participated in this

\section{Statement of Ethics}

The study was approved by the Ethics Committee of Peking University First Hospital, and informed consent was obtained from the participant included in the study.

\section{Disclosure Statement}

The authors have no conflicts of interest to declare.

\section{Funding Sources}

This work was supported by the National Natural Science Foundation of China (Nos. 91742205 and 81625004) and Peking University Clinical Scientist Program. The funders had no role in the study design, data collection and analysis, decision to publish, or preparation of the manuscript.

\section{Author Contributions}

Y.L.Z. analyzed and interpreted the patient data and drafted the manuscript. Li.Y. contributed to the conception and design of the study, interpretation of data, and made revision of the manuscript. J.W.H., T.S., Z.K.Y., X.J.Z., and X.Z.Z. were responsible for data collection. X.J.Y., H.W., S.X.W., and G.L. interpreted the pathological images. Liu.Y. illustrated the ophthalmological results. All authors read and approved the final manuscript.

\section{References}

1 Chawla LS, Bellomo R, Bihorac A, Goldstein SL, Siew ED, Bagshaw SM, et al. Acute kidney disease and renal recovery: consensus report of the Acute Disease Quality Initiative (ADQI) 16 Workgroup. Nat Rev Nephrol. 2017;13(4):241-57.

2 Mackensen F, Smith JR, Rosenbaum JT. Enhanced recognition, treatment, and prognosis of tubulointerstitial nephritis and uveitis syndrome. Ophthalmology. 2007;114(5):995-9.

3 Koike K, Lida S, Usui M, Matsumoto Y, Fukami K, Ueda S, et al. Adult-onset acute tubulointerstitial nephritis and uveitis with Fanconi syndrome. Case report and review of the literature. Clin Nephrol. 2007;67(4):255-9.

4 Mandeville JT, Levinson RD, Holland GN. The tubulointerstitial nephritis and uveitis syndrome. Surv Ophthalmol.2001;46(3):195208.

5 Shimamura Y, Tsushima T, Moniwa N, Hasegawa K, Ogawa Y, Takizawa H. Tubulointerstitial nephritis and uveitis syndrome complicated by IgA nephropathy and Graves' disease: a case report. J Med Case Rep. 2014; 8:305.

6 Yasuda K, Sasaki K, Yamato M, Rakugi H, Isaka Y, Hayashi T. Tubulointerstitial nephritis and uveitis syndrome with transient hyperthyroidism in an elderly patient. Clin Exp Nephrol. 2011;15(6):927-32.
7 Spronk PE, Weening JJ, Schut NH. Eosinophilic tubulo-interstitial nephritis associated with iridocyclitis and thyreoiditis. Neth J Med. 2001;59(1):35-8.

8 Mangat P, Jawad AS, Brownlee W. Tubulointerstitial nephritis uveitis syndrome associated with erosive arthropathy of the hip. Rheumatology. 2008;47(6):933-6.

9 Pascual J, Liano F, Mampaso F, Bellas C, Teruel JL, Ortuno J. IgA nephropathy and acute interstitial nephritis in a patient with relapsing uveitis and longstanding AS. J Rheumatol. 1991;18(6):942-5.

10 Albtoush OM, Springer F, Kolb M, Horger M. Tubulointerstitial Nephritis and Uveitis Syndrome with unilateral enthesopathy of the knee joint. Rofo. 2019;191(4):343-6.

11 Hofmann N, Müller KM, Morath C, Waldherr R, Zeier M, Schwenger V. Lymphoid interstitial lung disease in a patient with acute tubulointerstitial nephritis and uveitis: a new facet of a rare syndrome? Am J Kidney Dis. 2006;47(4):e55-9.

12 Catalano C, Harris PE, Enia G, Postorino M, Martorano C, Maggiore Q. Acute interstitial nephritis associated with uveitis and primary hypoparathyroidism. Am J Kidney Dis. 1989; 14(4):317-8.

13 Sugimoto T, Tanaka Y, Morita Y, Kume S, Uzu T, Kashiwagi A. Is tubulointerstitial nephritis and uveitis syndrome associated with IgG4-related systemic disease? Nephrology. 2008;13(1):89.
14 Simon AHR, Alves-Filho G, Almerinda M Ribeiro-Alves VF. Acute tubulointerstitial nephritis and uveitis with antineutrophil cytoplasmic antibody. Am J Kidney Dis. 1996; 28(1):124-7.

15 Hauser C, Kaya G, Chizzolini C. Nephrogenic fibrosing dermopathy in a renal transplant recipient with tubulointerstitial nephritis and uveitis. Dermatology. 2004;209(1):50-2.

16 Unal A, Sipahioglu MH, Akgun H, Yurci A, Tokgoz B, Erkilic K, et al. Crohn's disease complicated by granulomatous interstitial nephritis, choroidal neovascularization, and central retinal vein occlusion. Intern Med. 2008;47(2):103-7.

17 Das AS, Conway SE, Unizony SH, Bouffard MA, Rost NS, Venna N. Pearls \& oy-sters: neuro-sweet disease presenting as ischemic stroke and aseptic meningitis. Neurology. 2018;91(23):e2197-9.

18 Joss N, Morris S, Young B, Geddes C. Granulomatous interstitial nephritis, Clin J Am Soc Nephrol. 2007;2(2):222-30.

19 Nzerue C, Schlanger L, Jena M, Hewan-Lowe $\mathrm{K}$, Mitch WE. Granulomatous interstitial nephritis and uveitis presenting as salt-losing nephropathy, Am J Nephrol. 1997;17(5):462-5.

20 Nakai K, Fujii H, Hara S, Nishi S. Successful treatment of progressive renal injury due to granulomatous tubulointerstitial nephritis with uveitis. Clin Exp Nephrol. 2011; 15(5):765-8.

Zhao/Huang/Su/Yang/Zheng/Yang/

Zhou/Yu/Wang/Wang/Liu/Yang 
21 Segev A, Ben-Chitrit S, Orion Y, Segev F, Bernheim J, Bernheim J, et al. Acute eosinophilic interstitial nephritis and uveitis (TINU syndrome) associated with granulomatous hepatitis. Clin Nephrol. 1999;51(5):310-3.

22 Dobrin RS, Vernier RL, Fish AL. Acute eosinophilic interstitial nephritis and renal failure with bone marrow-lymph node granulomas and anterior uveitis. A new syndrome. Am J Med. 1975;59(3):325-33.

23 Fraga M, Nunes da Silva MJ, Lucas M, Victorino RM. Tubulointerstitial Nephritis and Uveitis Syndrome with non caseating granuloma in bone marrow biopsy. Acta Med Port. 2014;27(2):268-70.

24 Lessard M, Smith JD. Fanconi syndrome with uveitis in an adult woman. Am J Kidney Dis. 1989;13(2):158-9.

25 Belmouaz S, Sechet A, Fernandez B, Ayache RA, Desport E, Bauwens M, et al. Tubulo-interstitial nephritis with Fanconi syndrome in Behçet disease. Nephrol Dial Transplant. 2007;22(7):2079-83.

26 Vô B, Yombi JC, Aydin S, Demoulin N, Yildiz H. TINU-associated Fanconi syndrome: a case report and review of literature. BMC Nephrol. 2018;19(1):274.

27 Yao YH, Lin CC, Chung YM, Yang AH, Li SY, Lin CC, et al. Tubulointerstitial nephritis and uveitis syndrome (TINU) with Fanconi's syndrome. Clin Nephrol. 2011;75(Suppl 1):75-8.

28 Yao YH, Lin CC, Chung YM, Yang AH, Li SY, Lin CC, et al. Adult-onset acute tubulointerstitial nephritis and uveitis with Fanconi syndrome. Case report and review of the literature. Clin Nephrol. 2007;67(4):255-9.

29 Wen YK. Tubulointerstitial nephritis and uveitis with Fanconi syndrome in a patient with ankylosing spondylitis. Clin Nephrol. 2009;72(4):315-8.

30 Kamel M, Thajudeen B, Bracamonte E, Sussman A, Lien YH. Polyuric kidneys and uveitis: an oculorenal syndrome. Am J Case Rep. 2014;15:530-3.

31 Vidal E, Rogues AM, Aldigier JC. The Tinu syndrome or the Sjögren syndrome? Ann Intern Med. 1992;116(1):93.

32 Isobe $\mathrm{Y}$, Aritaka N, Setoguchi Y, Ito Y, Kimura H, Hamano Y, et al. T/NK cell type chronic active Epstein-Barr virus disease in adults: an underlying condition for Epstein-Barr virus-associated T/NK-cell lymphoma. J Clin Pathol. 2012;65(3):278-82.
33 Cigni A, Soro G, Faedda R, Caucci F, Amadori F, Manca A, et al. A case of adult-onset tubulointerstitial nephritis and uveitis ("TINU syndrome") associated with sacroileitis and Epstein-Barr virus infection with good spontaneous outcome. Am J Kidney Dis. 2003;42(3):E4-10.

34 Ljutic D, Glavina M. Tubulointerstitial nephritis with uveitis syndrome following varicella zoster reactivation. Nephron. 1995; 71(4):485-6.

35 Deguchi HE, Amemiya T. Two cases of uveitis with tubulointerstitial nephritis in HTLV-1 carriers. Jpn J Ophthalmol. 2003;47(4):372-8.

36 Stupp R, Mihatsch MJ, Matter L, Streuli RA. Acute tubulo-interstitial nephritis with uveitis (TINU syndrome) in a patient with serologic evidence for Chlamydia infection. Klin Wochenschr. 1990;68(19):971-5.

37 Suzuki H, Yoshioka K, Miyano M, Maeda I, Yamagami K, Morikawa T, et al. Tubulointerstitial nephritis and uveitis (TINU) syndrome caused by the Chinese herb "Goreisan". Clin Exp Nephrol. 2009;13(1):73-6.

38 Julián LK, Martínez-Cartier MD. Drug-induced tubulointerstitial nephritis and uveitis syndrome with posterior uveitis resembling acute posterior multifocal placoid pigment epitheliopathy. Retin Cases Brief Rep. 2010; 4(1):40-3.

39 Santoro D, Vita G, Rovito S, Venuto L, Cavallari V, Vita R, et al. Drug-induced TINU syndrome and genetic characterization. Clin Nephrol. 2012;78(3):230-6.

40 Sinangil A, Celik V, Kockar A, Ecder T. Synthetic cannabinoid induced acute tubulointerstitial nephritis and Uveitis Syndrome: a Case Report and Review of Literature. J Clin Diagn Res. 2016;10(5):Od31-2.

41 Uezono S, Hara S, Sato Y, Komatsu H, Ikeda $N$, Shimao Y, et al. Renal biopsy in elderly patients: a clinicopathological analysis. Ren Fail. 2006;28(7):549-55.

42 Haas M, Spargo BH, Wit EJ, Meehan SM. Etiologies and outcome of acute renal insufficiency in older adults: a renal biopsy study of 259 cases. Am J Kidney Dis. 2000;35(3):43347.

43 Lusco MA, Fogo AB, Najafian B, Alpers CE. AJKD atlas of renal pathology: thrombotic microangiopathy. Am J Kidney Dis. 2016; 68(6): $\mathrm{e} 33-4$.

44 J Charles J, Jean LO, Fred GS, Vivette DD. Heptinstall's pathology of the kidney. 7th ed. North Carolina: Chapel Hill; 2014.
45 Okafor LO, Hewins P, Murray PI, Denniston AK. Tubulointerstitial nephritis and uveitis (TINU) syndrome: a systematic review of its epidemiology, demographics and risk factors. Orphanet J Rare Dis. 2017;12(1):128.

46 Saarela V, Nuutinen M, Ala-Houhala M, Arikoski P, Rönnholm K, Jahnukainen T. Tubulointerstitial nephritis and uveitis syndrome in children: a prospective multicenter study. Ophthalmology. 2013;120(7):1476-81.

47 Tan Y, Yu F, Qu Z, Su T, Xing GQ, Wu LH, et al. Modified C-reactive protein might be a target autoantigen of TINU syndrome. Clin J Am Soc Nephrol. 2011;6(1):93-100.

48 Li C, Su T, Chu R, Li X, Yang L. Tubulointerstitial nephritis with uveitis in Chinese adults. Clin J Am Soc Nephrol. 2014;9(1):21-8.

49 Oliva-Damaso N, Oliva-Damaso E, Payan J. Acute and chronic tubulointerstitial nephritis of rheumatic causes. Rheum Dis Clin North Am. 2018;44(4):619-33.

50 Su T, Gu Y, Sun P, Tang J, Wang S, Liu G, et al. Etiology and renal outcomes of acute tubulointerstitial nephritis: a single-center prospective cohort study in China. Nephrol Dial Transplant. 2018;33(7):1180-8.

51 van den Born BJ, Koopmans RP, van Montfrans GA. The renin-angiotensin system in malignant hypertension revisited: plasma renin activity, microangiopathic hemolysis, and renal failure in malignant hypertension. Am J Hypertens. 2007;20(8):900-6.

52 Clive DM, Vanguri VK. The syndrome of tubulointerstitial nephritis with uveitis (TINU). Am J Kidney Dis. 2018;72(1):118-28.

53 Taheri S, Taheri D. Short course of cyclophosphamide therapy may reduce recurrence in patients with tubulointerstitial nephritis and uveitis syndrome. Saudi J Kidney Dis Transpl. 2009;20(4):655-7.

54 Kim JE, Park SJ, Oh JY, Jeong HJ, Kim JH, Shin JI. Successful treatment of tubulointerstitial nephritis and uveitis with steroid and azathioprine in a 12-year-old boy. Korean J Pediatr. 2016;59(Suppl 1):S99-S102.

55 Caplash S, Gangaputra S, Kodati S, Tuchman S, Srinivasalu H, Sen HN. Treatment challenges in an atypical presentation of tubulointerstitial nephritis and uveitis (TINU). Am J Ophthalmol Case Rep. 2018;10:253-6.

56 Sanchez-Burson J, Garcia-Porrua C, Montero-Granados R, Gonzalez-Escribano F, Gonzalez-Gay MA. Tubulointerstitial nephritis and uveitis syndrome in Southern Spain. Semin Arthritis Rheum. 2002;32(2):125-9.
AKI due to TINU Superimposed by

Thrombotic Microangiopathy
Kidney Dis 2020;6:414-421

DOI: $10.1159 / 000507668$ 